\title{
The relationship between unhealthy snacking at school and academic outcomes: a population study in Chilean schoolchildren
}

\author{
Paulina Correa-Burrows*, Raquel Burrows, Yasna Orellana and Daniza Ivanovic \\ Institute of Nutrition and Food Technology, University of Chile, Avda. El Líbano 5524, Macul, CP 7830490, \\ Santiago de Chile, Chile
}

Submitted 17 January 2014: Final revision received 10 September 2014: Accepted 10 October 2014: First published online 3 December 2014

\begin{abstract}
Objective: We examined the association between unhealthy snacking at school and academic outcomes in students from the Santiago Metropolitan Region (Chile).

Design: Cross-sectional population-based study.

Setting: We measured the nutritional quality of snacks at school using an FFQ, and accounting for the amounts of saturated fat, fibre, sugar and salt in the foods, and academic outcomes using national standardized test scores in Language and Mathematics. Multivariate regression analyses modelled the relationship between unhealthy snacking at school (exposure), potential confounders and performance in Mathematics and Language (outcomes).

Subjects: Random sample of 1073 students (13.1 (SD 2.3) years old) attending public, partially subsidized and private schools.

Results: Fifty-six per cent of students ate items at snack time that were high in fat, sugar, salt and energy, and thus were considered to have unhealthy snaking. Thirty-six per cent and $8 \%$ were considered to have poor-to-fair and healthy snacking, respectively. Unhealthy snacking significantly lowered the odds of good academic performance in both domains. Students having unhealthy snacks were $56 \%$ less likely to pass in Language (fully adjusted OR $=0.44 ; 95 \%$ CI 0.23, 0.85) and $66 \%$ less likely to pass in Mathematics (fully adjusted OR $=0 \cdot 34 ; 95 \%$ CI 0.19, 0.64) compared with students having healthy snack items.

Conclusions: Schoolchildren eating unhealthy foods at snack time had worse academic performance in Language and Mathematics, as measured by a standardized test. Although association does not imply causation, these findings support the notion that academic and health-related behaviours are linked. More research is needed on the effect of school health programmes on educational outcomes.
\end{abstract}

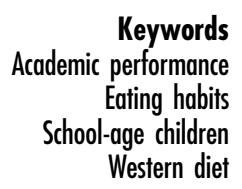

Most research studies performed in developing and middleincome countries have examined the association between macro- and micronutrient deficiencies and several measures of cognitive functioning in children ${ }^{(1-3)}$. The economic boom of the past two decades, however, has paved the way for an increase in non-communicable diseases associated with overweight and obesity since infancy. The consumption of salty, sugary and high-fat processed foods, major elements of the so-called Western diet, which contribute to excessive nutrient intake and weight gain, is becoming extremely prevalent among school-age children from these countries $^{(4)}$. This is a subject of huge concern for public health officials, academics and all those struggling against the obesity epidemic ${ }^{(5)}$.

The Western diet does not merely lead to obesity and cardiovascular and metabolic disorders. Studies in both animal and human models have found evidence for an association between cognitive functioning and excess consumption of the macronutrients that are the primary components of the Western diet. They indicate that excessive intakes of saturated fats and simple carbohydrates are related to impairment in several learning and memory processes dependent on the hippocampus ${ }^{(6-10)}$. Exposure to these macronutrients interferes with hippocampal functioning directly, by cutting down the production of neurotrophins, increasing the level of neuroinflammatory markers and altering the blood-brain barrier, and indirectly by impairing glucose regulation ${ }^{(11-13)}$.

With the exclusion of research about the effect of breast-feeding on cognitive evolution and/or functioning later in life, few works have addressed the cognitive impact of dietary rules in children rather than focusing on 
individual nutrients, the predominant approach to studying this subject. In the UK, the Avon Longitudinal Study of Parents and Children (ALSPAC) has offered evidence suggesting that unhealthy dietary practices during early childhood have a lasting association with intelligence in mid-childhood and adolescence ${ }^{(14-16)}$. Similarly, in children from New Zealand, Theodore et al. found a positive relationship between cognitive abilities and dietary patterns at 3.5 and 7 years of age ${ }^{(17)}$, whereas Nyaradi et al. reported that Australian children with better diet quality during the early years of life showed higher verbal and non-verbal abilities later in mid-childhood ${ }^{(18)}$.

The nutritional quality of food and meal patterns is related to specific outcomes that are important for the educational attainment of children and teens. Studies of nutrition and academic performance and/or behaviour have typically focused on the effect of malnutrition and micronutrient deficiency ${ }^{(19,20)}$. Very few have addressed the effect of overnutrition and they have been mostly carried out in developed countries ${ }^{(21-25)}$. Due to the lack of evidence from countries undergoing transitional processes, the aim of the present study was to examine the association between diet as a composite measure and academic outcomes in children from Chile, a middleincome country that underwent a profound shift from under- to overnutrition in less than two decades ${ }^{(26-28)}$. Specifically, we examined the relationship between unhealthy snacking at school and the ability to perform in Language and Mathematics. We hypothesized that an increase in consumption of unhealthy food items during snack time would be associated with poor academic outcomes in both domains.

\section{Methods}

\section{Study population and sample selection}

The target population, 187860 children $(39 \%$ of the Chilean school-age population), included all students enrolled in 5th ( $n 91663)$ and 9th ( $n 96197)$ grade in the Santiago Metropolitan Region in 2010 and who took the national standardized System for the Assessment of Educational Quality test (herein SIMCE) in 2009. They attended public, partially subsidized and private schools from urban areas.

The sampling frame of the study corresponds to the educational establishments from the Santiago Metropolitan Region. The sampling system was performed in two stages. In the first stage, thirty-three educational establishments accounting for $2.6 \%$ of the total urban school population ( $n$ 1262) were randomly selected by proportional allocation according to the type of school and level of achievement in the SIMCE 2009 as established by the Ministry of Education (high-, mid- and low-achieving). In a second stage, in each of the thirty-three schools, students enrolled in both grades who took the SIMCE 2009 were invited to participate in the study. A total of 1277 schoolage children and their parents agreed to participate and signed the informed consent form. Two hundred and four students were excluded because they did not provide full information on their eating habits or because they did not attend the SIMCE examination. Thus, the final sample included 1074 participants, $84 \%$ of the original data set.

The study was approved by the Committee on Ethics in Studies in Humans of the Institute of Nutrition and Food Technology (INTA), University of Chile, and the Committee on Bioethics of the National Fund for Scientific and Technologic Development (FONDECYT), Chile. The field study was carried out during academic year 2010.

\section{Snacking at school}

Nutritional quality of items consumed during the snack time at school was measured accounting for the amounts of saturated fat, fibre, sugar and salt in the foods. We used an FFQ validated in previous studies ${ }^{(29,30)}$ that was administered by a researcher to all students at the time they attended the anthropometric examination. Students in 9th grade answered by themselves whereas 5th graders answered with their parents' help. The questions and response categories were identical in both groups. The questionnaire was designed to assess the habitual diet during the school day (rather than the whole diet), by asking about the frequency of food consumption. A list of twenty-five items, including foods and beverages, was used. The frequency of food consumption was assessed by a multiple response grid in which respondents were asked to estimate how often a particular food or beverage was consumed. Categories ranging from 'never' to 'five times a week' were used and participants had to choose one of these options. A computerized software based on the Chilean Food Composition Tables 2010 edition $^{(31)}$ calculated nutrient intakes by multiplying the reported frequency of each food item by the amounts of nutrients in a serving of that food item. Depending on the amounts of saturated fat, fibre, sugar and salt in the foods, snacking at school was considered to be unhealthy (items of poor nutritional value and high in fat, sugar, salt and energy), poor-to-fair (highly processed items although low in fat) and healthy (nutrient-rich items and protective foods).

\section{Academic performance}

Academic performance in Mathematics and Language was assessed using the national standardized SIMCE test, which has national coverage in Chile and is administered by the Ministry of Education to all students attending 4th and 8th grade. SIMCE consists of four major tests: Language, Mathematics, Science and Social Science. Each test, made up of multiple-choice items as well as open-ended questions, receives a score on the scale of $0-400$. In order to perform this analysis, scores in Language and Mathematics were categorized according to the achievement levels established by the Ministry of Education. Thus, the minimum score to 
pass in Language was 241 in 4th grade and 235 in 8th grade, whereas in Mathematics it was 233 in 4th grade and 276 in 8 th grade. Since the SIMCE tests were taken prior to the field study, we used personal identification codes to link SIMCE scores to students' anthropometric, socio-economic and dietary pattern data.

\section{School's performance}

All schools were categorized by the Chilean Ministry of Education into three levels, namely low-achieving schools, mid-achieving schools and high-achieving schools, based upon the performance of their students in all SIMCE tests ${ }^{(32)}$.

\section{Anthropometric measurements and nutritional status}

Standardized procedures were used to measure students' weight to the nearest $0.1 \mathrm{~kg}$, using a Seca scale (SECA, Hamburg, Germany), and height to the nearest $0 \cdot 1 \mathrm{~cm}$, using a Holtain stadiometer. All instruments were verified before measuring each participant ${ }^{(33)}$. BMI $\left(\mathrm{kg} / \mathrm{m}^{2}\right)$ and height-forage were evaluated, and $Z$-scores were obtained according to the references of the Centers for Disease Control, National Center for Health Statistics (USA) ${ }^{(34)}$. Nutritional status was defined as follows: underweight, BMI $Z$-score $<-1$; normal weight, BMI $Z$-score from -1 to +1 ; overweight, BMI $Z$-score from +1 to $+<2$; and obesity, BMI $Z$-score $\geq+2$.

\section{Socio-economic status}

Socio-economic status (SES) was measured using a scale based on Graffar's modified method which was adapted to Chilean urban and rural populations ${ }^{(35)}$. This scale classified the sample into five socio-economic groups: $1=$ high $(0.3 \%) ; \quad 2=$ mid-high $\quad(14.7 \%) ; \quad 3=$ middle $\quad(38.3 \%)$; $4=$ mid-low $(45 \cdot 6 \%)$; and $5=$ low $(1 \cdot 1 \%)$. However, in our analysis we merged these five categories into three: high $(1+2)$, middle (3) and low $(4+5)$ SES.

\section{Statistical analysis}

Statistical analysis included performing $\chi^{2}$ tests to compare categorical variables, and ANOVA and Bonferroni tests for comparison of continuous variables. After performing bivariate analyses with each potential confounding variable, including sex, grade, nutritional status, SES and school's performance, we used logistic regression to assess the relationship between the nutritional quality of snacks at school (exposure) and individual academic performance in Mathematics and Language (outcome). In each case, the probability of passing the test was estimated using three models. The first one included the nutritional quality of snacks, sex, grade and a variable denoting nutritional status (overweight/obesity $=$ BMI $Z$-score $\geq+1$ ). In the second model, SES was added. Finally, a fully adjusted model contained all mentioned covariates with the addition of a variable denoting the school's academic performance. Because the variable school's performance was partly derived from the outcome variables, this adjustment may cause underestimation of the association, so we included models with and without adjustment for school's performance. A $P$ value of $<0.05$ denoted statistical significance. Data were processed using the statistical software package Stata SE for Windows version 12.0.

\section{Results}

Our sample was made up of $13 \cdot 1$ (sD $2 \cdot 3$ ) year-old male $(52 \%)$ and female (48\%) adolescents of low (44.3\%), middle (39.6\%) and high (16.1\%) SES. They attended 5 th $(51.9 \%)$ and 9 th (48.1\%) grade in public $(34.8 \%)$, partially subsidized (57.8\%) and private schools (7.4\%) in the Santiago Metropolitan Region. As for nutritional status, $45 \%$ of participants were overweight or obese. Nearly half of the students (48\%) attended high-achieving schools, whereas $29 \%$ and $23 \%$ attended mid- and low-achieving schools, respectively.

In the sample, $56 \%$ of students reported consumption of items at snack time that were high in fat, sugar, salt and energy. Thirty-six per cent were regarded to have poor-tofair snacking, whereas just $8 \%$ were considered to eat healthy items during the snack time at school. Table 1 contains the descriptive statistics of the sample. Average values of scores in Language and Mathematics were significantly decreased among those with lower nutritional quality of snacks at school $(P=0 \cdot 01)$. The share of students consuming unhealthy snacks at school was significantly higher among 9th graders (59\%; $P=0 \cdot 040)$, students attending low-achieving schools $(61 \% ; P=0.036)$, as well as among underweight and normal-weight participants $(69 \%$ and $62 \%$, respectively; $P=0.006$ ).

As shown in Table 2, the proportions of students who passed the standardized Mathematics and Language tests were significantly higher among students having healthy snacks at school $(P=0.015$ and $P=0.041$, respectively). Sex $(P<0.0001)$ and overweight/obese status $(P=0 \cdot 017)$ were both significantly associated with outcomes in Mathematics, whereas performance in Language was significantly associated with grade $(P<0 \cdot 0001)$. We likewise found a substantial relationship between performance in the standardized tests and SES $(P=0.01)$ and the school's performance $(P<0 \cdot 0001)$.

Table 3 shows the association between academic outcomes in Mathematics and nutritional quality of snacking at school. After adjusting for sex, grade and overweight, students eating unhealthy foods had significantly lower odds of good academic performance. Compared with the students eating healthy snack foods, the odds of passing the test were lower among students having unhealthy snacks at school $(\mathrm{OR}=0.46 ; 95 \% \mathrm{CI} 0 \cdot 26,0 \cdot 80)$. We likewise found that performance in the test was also associated with sex and overweight/obesity. When SES was added as a covariate, the association between academic performance in Mathematics and nutritional quality of snacks remained significant 
Table 1 Descriptive statistics of the sample by nutritional quality of snacks at school; random sample 5th and 9th grade students ( $n$ 1073) attending public, partially subsidized and private schools in Santiago Metropolitan Region, Chile, 2010

\begin{tabular}{|c|c|c|c|c|c|c|c|}
\hline & \multicolumn{2}{|c|}{ Unhealthy snacking ( $n$ 602) } & \multicolumn{2}{|c|}{ Poor-to-fair snacking ( $n$ 391) } & \multicolumn{2}{|c|}{ Healthy snacking ( $n$ 80) } & \multirow[b]{2}{*}{$P$ value } \\
\hline & Mean or \% & SD or $95 \% \mathrm{Cl}$ & Mean or \% & SD or $95 \% \mathrm{Cl}$ & Mean or $\%$ & SD or $95 \% \mathrm{Cl}$ & \\
\hline \multicolumn{8}{|l|}{ Chronological age } \\
\hline Age (years) & $13 \cdot 3$ & $2 \cdot 3$ & 13.0 & $2 \cdot 3$ & 13.4 & $2 \cdot 3$ & NS \\
\hline \multicolumn{8}{|l|}{ Sex } \\
\hline Male & $59 \cdot 0$ & $54 \cdot 9,63 \cdot 1$ & 33.7 & $29 \cdot 8,37 \cdot 6$ & $7 \cdot 4$ & $5 \cdot 2,9 \cdot 5$ & \multirow[t]{2}{*}{ NS } \\
\hline Female & 53.0 & $48 \cdot 7,57 \cdot 3$ & 39.4 & $35 \cdot 2,43 \cdot 6$ & $7 \cdot 6$ & $5 \cdot 3,9 \cdot 8$ & \\
\hline \multicolumn{8}{|l|}{ Nutritional status } \\
\hline Underweight & $69 \cdot 2$ & $51 \cdot 1,87 \cdot 3$ & $26 \cdot 9$ & $9 \cdot 5,44 \cdot 3$ & 3.9 & $3 \cdot 7,11 \cdot 3$ & \multirow{4}{*}{$0.006 \S$} \\
\hline Normal & 61.5 & $57 \cdot 2,65 \cdot 3$ & 31.9 & $28 \cdot 1,35 \cdot 8$ & $6 \cdot 8$ & $4.7,8.9$ & \\
\hline Overweight & 51.5 & $45 \cdot 8,65 \cdot 2$ & $40 \cdot 0$ & $34.4,45 \cdot 6$ & 8.5 & $5 \cdot 3,11.6$ & \\
\hline Obese & $46 \cdot 4$ & $39 \cdot 3,53 \cdot 4$ & $45 \cdot 2$ & $38 \cdot 2,52 \cdot 4$ & 8.3 & $4 \cdot 4,12 \cdot 3$ & \\
\hline \multicolumn{8}{|c|}{ Academic performance (SIMCE) } \\
\hline Mathematics (raw value) & 272.7 & 57.5 & 281.8 & $53 \cdot 1$ & 290.0 & $52 \cdot 0$ & 0.005 \\
\hline Language (raw value) & 268.7 & $52 \cdot 1$ & $279 \cdot 1$ & $50 \cdot 7$ & 281.3 & $49 \cdot 0$ & 0.004 \\
\hline Mathematics (Z-score) & -0.20 & 1.0 & 0.01 & 1.0 & 0.92 & 1.0 & 0.001 \\
\hline Language (Z-score) & -0.15 & 1.0 & 0.5 & 1.0 & 0.07 & 1.0 & 0.004 \\
\hline \multicolumn{8}{|l|}{ Graed } \\
\hline 5 th & 53.7 & $49 \cdot 5,57 \cdot 8$ & 39.9 & $35 \cdot 8,43.9$ & $6 \cdot 5$ & $4.4,8.5$ & \multirow[t]{2}{*}{$0.040 \S$} \\
\hline 9th & 58.7 & $54.4,62.9$ & $32 \cdot 8$ & $28 \cdot 7,36 \cdot 8$ & 8.5 & $6 \cdot 1,10.9$ & \\
\hline \multicolumn{8}{|l|}{ Socio-economic status } \\
\hline High & $49 \cdot 1$ & $41 \cdot 6,56 \cdot 6$ & 41.6 & $34 \cdot 2,49 \cdot 0$ & $9 \cdot 3$ & $4.9,13.6$ & \multirow[t]{3}{*}{ NS } \\
\hline Middle & $58 \cdot 1$ & $53 \cdot 4,62 \cdot 8$ & $36 \cdot 7$ & $32 \cdot 1,41 \cdot 3$ & $5 \cdot 2$ & $3 \cdot 1,7 \cdot 2$ & \\
\hline Low & $56 \cdot 8$ & $52 \cdot 3,61 \cdot 2$ & $34 \cdot 3$ & $30 \cdot 0,38 \cdot 6$ & $8 \cdot \overline{8}$ & $6 \cdot 3,11 \cdot 4$ & \\
\hline \multicolumn{8}{|l|}{ School's performance } \\
\hline High-achieving school & $52 \cdot 7$ & $48 \cdot 4,57 \cdot 0$ & $40 \cdot 1$ & $35 \cdot 8,44 \cdot 3$ & $7 \cdot 2$ & $5 \cdot 0,9 \cdot 4$ & \multirow[t]{3}{*}{$0.036 \S$} \\
\hline Mid-achieving school & $57 \cdot 7$ & $52 \cdot 2,63 \cdot 1$ & $36 \cdot 2$ & $30 \cdot 1,41 \cdot 6$ & $6 \cdot 1$ & $3.4,8.8$ & \\
\hline Low-achieving school & $61 \cdot 1$ & $55 \cdot 0,67 \cdot 2$ & 29.2 & $23 \cdot 5,44 \cdot 8$ & 9.7 & $6 \cdot 0,13 \cdot 4$ & \\
\hline
\end{tabular}

SIMCE, System for the Assessment of Education Quality.

Values are presented as mean and standard deviation for continuous variables or as percentage and $95 \%$ confidence interval for categorical variables.

t $P$ values from one-way ANOVA, except as indicated.

$¥$ School performance defined according to the Ministry of Education.

$\S P$ values from $X^{2}$ test (Pearson).

Table 2 Academic performance in the SIMCE (Mathematics and Language) by selected covariates; random sample 5th and 9th grade students ( $n$ 1073) attending public, partially subsidized and private schools in Santiago Metropolitan Region, Chile, 2010

\begin{tabular}{|c|c|c|c|c|c|c|c|c|}
\hline & \multicolumn{8}{|c|}{ Students who passed the SIMCE test } \\
\hline & \multicolumn{4}{|c|}{ Mathematics } & \multicolumn{4}{|c|}{ Language } \\
\hline & Frequency & $\%$ & OR & $95 \% \mathrm{Cl}$ & Frequency & $\%$ & OR & $95 \% \mathrm{Cl}$ \\
\hline Overall & 733 & $68 \cdot 3$ & - & - & 816 & $76 \cdot 3$ & - & - \\
\hline \multicolumn{9}{|l|}{ Sex } \\
\hline Male & 418 & 74.9 & Ref. & - & 431 & $77 \cdot 0$ & Ref. & - \\
\hline Female & 315 & $61 \cdot 2$ & $0.53^{\star \star \star}$ & $0.41,0.69$ & 385 & $75 \cdot 6$ & 0.93 & $0.70,1 \cdot 23$ \\
\hline \multicolumn{9}{|l|}{ Grade } \\
\hline 5 th grade & 394 & $70 \cdot 5$ & Ref. & - & 399 & $71 \cdot 8$ & Ref. & - \\
\hline 9th grade & 339 & $65 \cdot 7$ & 0.79 & $0.61,1.02$ & 417 & $81 \cdot 3$ & $1 \cdot 71^{\star \star \star}$ & $1 \cdot 28,2 \cdot 28$ \\
\hline \multicolumn{9}{|l|}{ Overweight/obesity† } \\
\hline No & 449 & $71 \cdot 2$ & Ref. & - & 492 & $78 \cdot 5$ & Ref. & - \\
\hline Yes & 284 & 64.3 & $0.72^{\star}$ & $0.56,0.94$ & 324 & 73.3 & $0.75^{\star}$ & $0.57,0.98$ \\
\hline \multicolumn{9}{|l|}{ Socio-economic status } \\
\hline High & 148 & $85 \cdot 6$ & Ref. & - & 152 & 89.9 & Ref. & - \\
\hline Middle & 321 & $75 \cdot 6$ & $0.52^{\star \star}$ & $0.32,0.84$ & 340 & $80 \cdot 0$ & $0.45^{\star \star}$ & $0.26,0.78$ \\
\hline Low & 264 & $55 \cdot 6$ & $0 \cdot 21^{\star \star \star}$ & $0.13,0.34$ & 324 & $68 \cdot 2$ & $0 \cdot 24^{\star \star \star}$ & $0.14,0.41$ \\
\hline \multicolumn{9}{|l|}{ School's performance } \\
\hline High-achieving school & 445 & $86 \cdot 6$ & Ref. & - & 466 & $91 \cdot 2$ & Ref. & - \\
\hline Mid-achieving school & 195 & 62.5 & $0.26^{\star \star \star}$ & $0.18,0.36$ & 218 & $70 \cdot 1$ & $0.23^{\star \star \star}$ & $0.15,0.33$ \\
\hline Low-achieving school & 93 & $37 \cdot 3$ & $0.09^{\star \star *}$ & $0.06,0.13$ & 132 & 53.4 & $0.11^{\star * *}$ & $0.07,0.16$ \\
\hline \multicolumn{9}{|c|}{ Nutritional quality of snacking } \\
\hline Healthy & 62 & 77.5 & Ref. & - & 69 & 84.2 & Ref. & - \\
\hline Poor-to-fair & 289 & 73.9 & 0.82 & $0.46,1.45$ & 305 & 79.0 & 0.72 & $0.28,1.34$ \\
\hline Unhealthy & 382 & 63.5 & $0.50^{*}$ & $0.29,0.47$ & 442 & 73.5 & $0.51^{*}$ & $0.37,0.97$ \\
\hline
\end{tabular}

SIMCE, System for the Assessment of Education Quality; Ref., referent category.

${ }^{*}$ Significance at the 0.05 level, ${ }^{* *}$ significance at the 0.01 level, ${ }^{* * *}$ significance at the 0.001 level.

†Overweight and obesity: BMI Z-score for age and sex $\geq+1$.

¥School performance defined according to the Ministry of Education. 
Table 3 Relationship between individual academic performance in Mathematics and nutritional quality of school snacking, after controlling sociodemographic, health and educational confounders; random sample 5th and 9th grade students $(n$ 1073) attending public, partially subsidized and private schools in Santiago Metropolitan Region, Chile, 2010

\begin{tabular}{|c|c|c|c|c|c|c|}
\hline & \multicolumn{2}{|c|}{ Model 1} & \multicolumn{2}{|c|}{ Model 2} & \multicolumn{2}{|c|}{ Model 3} \\
\hline & OR & $95 \% \mathrm{Cl}$ & OR & $95 \% \mathrm{Cl}$ & OR & $95 \% \mathrm{Cl}$ \\
\hline Unhealthy snacking & $0.46^{*}$ & $0.26,0.80$ & $0.41^{* *}$ & $0.23,0.73$ & $0.34^{\star *}$ & $0.19,0.64$ \\
\hline Poor-to-fair snacking & 0.82 & $0.46,1.46$ & 0.72 & $0.40,1.30$ & 0.57 & $0.30,1.07$ \\
\hline Sex (female) & $0.50^{\star \star \star}$ & $0.39,0.66$ & $0.54^{\star \star \star}$ & $0.41,0.71$ & $0.55^{\star \star \star}$ & $0.41,0.74$ \\
\hline Grade (9th) & 0.78 & $0.59,1.03$ & $0 \cdot 70^{\star}$ & $0.53,0.92$ & $0.63^{\star \star}$ & $0.46,0.85$ \\
\hline Overweight/obesity $\dagger$ & $0.65^{\star *}$ & $0.49,0.85$ & $0.68^{* *}$ & $0.51,0.90$ & $0.65^{\star \star}$ & $0.48,0.86$ \\
\hline Low socio-economic status & - & - & $0.34^{\star \star \star}$ & $0.26,0.45$ & $0.46^{\star \star \star}$ & $0.34,0.61$ \\
\hline Low-achieving schoolł & - & - & - & - & $0.20^{\star \star \star}$ & $0.15,0.28$ \\
\hline Observations & \multirow{4}{*}{\multicolumn{2}{|c|}{$\begin{array}{c}1073 \\
53.66^{\star \star \star} \\
16.53(P=0.03) \\
69.7\end{array}$}} & \multicolumn{2}{|c|}{1073} & \multicolumn{2}{|c|}{1073} \\
\hline Likelihood ratio $\left(x^{2}\right)$ & & & & & \multirow{2}{*}{\multicolumn{2}{|c|}{$\begin{array}{c}209.61^{\star * *} \\
3.77(P=0.88)\end{array}$}} \\
\hline Hosmer-Lemeshow & & & & $0.68)$ & & \\
\hline Correctly classified (\%) & & & \multicolumn{2}{|c|}{70.4} & & \\
\hline
\end{tabular}

${ }^{*}$ Significance at the 0.05 level, ${ }^{\star *}$ significance at the 0.01 levels ${ }^{\star \star *}$ significance at the 0.001 level.

†Overweight/obesity: BMI Z-score for age and sex $\geq+1$.

fLow-achieving school: definition according to the Ministry of Education.

Table 4 Relationship between individual academic performance in Language and nutritional quality of school snacking, after controlling sociodemographic, health and educational confounders; random sample 5th and 9th grade students $(n 1073)$ attending public, partially subsidized and private schools in Santiago Metropolitan Region, Chile, 2010

\begin{tabular}{|c|c|c|c|c|c|c|}
\hline & \multicolumn{2}{|c|}{ Model 1} & \multicolumn{2}{|c|}{ Model 2} & \multicolumn{2}{|c|}{ Model 3} \\
\hline & OR & $95 \% \mathrm{Cl}$ & OR & $95 \% \mathrm{Cl}$ & OR & $95 \% \mathrm{Cl}$ \\
\hline Unhealthy snacking & $0.52^{*}$ & $0.28,0.97$ & $0.49^{*}$ & $0.26,0.93$ & $0.44^{*}$ & $0.23,0.85$ \\
\hline Poor-to-fair snacking & 0.76 & $0.38,1.45$ & 0.69 & $0.36,1.34$ & 0.58 & $0.29,1.15$ \\
\hline Sex (female) & 0.88 & $0.66,1.17$ & 0.94 & $0.71,1.26$ & 1.02 & $0.75,1.38$ \\
\hline Grade (5th) & $0.59^{\star \star \star}$ & $0.44,0.79$ & $0.62^{\star \star}$ & $0.46,0.84$ & $0.63^{\star \star}$ & $0.47,0.87$ \\
\hline Overweight/obesity† & 0.78 & $0.58,1.04$ & 0.81 & $0.61,1.10$ & 0.79 & $0.45,0.85$ \\
\hline Low socio-economic status & - & - & $0.47^{\star \star \star}$ & $0.35,0.62$ & $0.62^{\star \star}$ & $0.45,0.85$ \\
\hline Low-achieving schoolł & - & - & - & - & $0.26^{\star \star \star}$ & $0.19,0.36$ \\
\hline Observations & \multirow{2}{*}{\multicolumn{2}{|c|}{$\begin{array}{c}1069 \\
23 \cdot 90^{\star \star \star *}\end{array}$}} & \multirow{2}{*}{\multicolumn{2}{|c|}{1069}} & \multicolumn{2}{|c|}{1069} \\
\hline Likelihood ratio $\left(x^{2}\right)$ & & & & & \multirow{2}{*}{\multicolumn{2}{|c|}{$5.41(P=0.71)$}} \\
\hline Hosmer-Lemeshow & \multicolumn{2}{|c|}{$1.59(P=0.99)$} & \multicolumn{2}{|c|}{$5.12(P=0.75)$} & & \\
\hline Correctly classified (\%) & \multicolumn{2}{|c|}{$76 \cdot 33$} & \multicolumn{2}{|c|}{$76 \cdot 33$} & \multicolumn{2}{|c|}{77.08} \\
\hline
\end{tabular}

${ }^{*}$ Significance at the 0.05 level, ${ }^{* *}$ significance at the 0.01 level, ${ }^{* \star *}$ significance at the 0.001 level.

†Overweight/obesity: BMI Z-score for age and sex $\geq+1$.

łLow-achieving school: definition according to the Ministry of Education.

$(\mathrm{OR}=0.41 ; 95 \% \mathrm{CI} 0.23,0.73)$ and similarly the association with sex and overweight/obesity. In this model we also found a significant relationship with grade and SES. Lastly, after full adjustments, the odds of passing the test remained significantly lower among students eating unhealthy snacks $(\mathrm{OR}=0.34 ; 95 \% \mathrm{CI} 0.19,0.64)$. An association with the school's performance was found, while sex, grade, overweight and SES remained associated.

The results of students' performance in Language are given in Table 4. In the first model, the association between academic performance and nutritional quality of snacks was significant. Students eating items rich in salt, simple sugars and saturated fat were $48 \%$ less likely $(\mathrm{OR}=0.52 ; 95 \% \mathrm{CI} 0.28,0.97)$ to pass the standardized test compared with students eating nutrient-rich items. Attainment in Language was associated with grade, but the association with sex and overweight/obesity was insignificant. By adding SES as a covariate, the association between academic performance and nutritional quality of snacks remained significant $(\mathrm{OR}=0 \cdot 49,95 \% \mathrm{CI} 0 \cdot 26,0 \cdot 93)$ and, similarly, the association with grade. The relationship with SES was significant as well. In the fully adjusted model, students having unhealthy food items at school remained less likely to pass the standardized test compared with their peers consuming healthy foods $(\mathrm{OR}=0.44 ; 95 \% \mathrm{CI} 0 \cdot 23,0 \cdot 85)$. The relationship between performance in this domain with grade and SES remained significant in this model, whereas a significant link to the school's performance was found.

\section{Discussion}

\section{Main conclusions}

Our findings show that unhealthy snacking is remarkably widespread among Chilean students. In our sample, less than $10 \%$ were considered to have healthy snacking at school (i.e. consumption of nutrient-rich items and 
protective foods on a daily basis). At the same time, more than a half ate energy-dense snacks, rich in simple sugars and saturated fat. In 2010, Bustos et al. studied eating habits during snack time in 10-13-year-old children attending public schools $(n \text { 668 })^{(36)}$. Fifty-nine per cent used to buy food items at the school kiosk on a daily basis, mostly sweet snacks (35\%), sugary drinks, ice creams (33\%) and salty snacks $(30 \%)$. A few years earlier, Olivares et al. reported that $35 \%$ of Chilean students aged 10-13 years had always money to buy food items at the school kiosk whereas $64 \%$ had money from their parents at least three times per week ${ }^{(37)}$. With the money, $68 \%$ of the children used to buy sweet and salted products, $17 \%$ bought soft drinks, $6 \%$ bought yoghurt and $4 \%$ bought fast food.

Chilean students are persistently exposed to a huge number of unhealthy food products, so snacking accounts for a considerable proportion of energy intake during the day. In almost every single school, there is a kiosk cart and a cafeteria-style food service that is open for luncheon and during recess time and after-school programmes. Very few districts within the Santiago Metropolitan Region are taking genuine steps towards healthier eating in schools by providing so-called 'healthy spaces'. These are kiosks and cafeterias whose supply is made up of $70 \%$ healthy foods (less than $544 \mathrm{~kJ}$ (130 kcal), $3 \mathrm{~g}$ of fat, $20 \mathrm{~g}$ of carbohydrates and $140 \mathrm{mg}$ of $\mathrm{Na}$ per serving) at convenient prices $^{(38)}$. In fact, price and the lack of availability of healthier food choices are among the main barriers to healthy snacking in elementary-school settings ${ }^{(39)}$.

A second major finding is the positive association between nutritional quality of school snacking and academic outcomes in school-age children. In our sample, participants having unhealthy snacking showed significantly lower performance in Mathematics and Language compared with students eating nutrient-rich snacks. Consumption of refined carbohydrates and SFA has been related to poorer cognitive performance in both children ${ }^{(14-18)}$ and adolescents ${ }^{(16,40,41)}$. According to studies carried out in both animal and human models, these two macronutrients interfere with synaptic plasticity and neurogenesis in the hippocampus and the medial prefrontal cortex, disrupting high-ordered learning and memory processes ${ }^{(13,42,43)}$.

Also, our results are in line with those obtained by previous studies in various population samples of children. Sigfúsdóttir et al. and Kristjánsson et al. analysed survey data from Icelandic 9th and 10th graders to explore the relationship between selected health behaviours and academic outcomes ${ }^{(21,22)}$. They found that performance in Icelandic, Mathematics and foreign languages was negatively influenced by poor dietary habits, although both studies used self-reported averaged grades to measure academic outcomes. In Norwegian 9th and 10th grade adolescents ( $n$ 475), Øverby et al. observed that a high intake of foods representing a poor diet was significantly associated with increased odds of mathematical difficulties ${ }^{(23)}$. In previous research using the same sample, $\varnothing$ verby and Høigaard had found that receiving an optimal diet was linked with decreased odds of behavioural problems at school ${ }^{(24)}$. Among 5200 children in 5th grade from Nova Scotia, Canada, Florence et al. reported a positive association between diet quality and academic performance in the standardized Elementary Literacy Assessment. Students with decreased overall diet quality and higher energy intake from fat were significantly more likely to perform badly on both the reading and the writing assessments $^{(25)}$. Finally, using longitudinal data from ALSPAC and different measures of school performance, Feinstein et al. found that the 'junk food' dietary pattern at 3,4 and 7 years of age was negatively associated with performance on entry assessments to school and the national standardized Key Stage 1 and Key Stage 2 tests, administered when children are aged 6-7 years and 10-11 years, respectively. Furthermore, the impact of that pattern at age 3 years recorded the greatest magnitude on the three indicators of academic outcome, suggesting that early feeding patterns have implications for academic outcomes that seem to run over time, irrespective of subsequent modifications in diet ${ }^{(44)}$. All of these research studies used similar definitions of unhealthy foods and dietary habits. Less healthy foods are normally identified as those that are higher in processed carbohydrate and/or saturated fat and low in vitamins and minerals, such as sugar-sweetened soft drinks, sweets, chocolate, savoury snacks and high-fat processed foods.

Some comments should be made on the effect of nutritional status on the outcome variables. In a growing number of studies, school performance of overweight children has been found to be lower compared with that of normal-weight children, although the grounds for this relationship are debated ${ }^{(45-47)}$. In our sample, overweight/ obesity status increased the odds of academic difficulties, but only the association with Mathematics was significant.

Likewise, determinants such as social background and family support, which affect students' academic performance, have also been found to be linked to children's eating patterns ${ }^{(48-52)}$. In our sample, the consumption of unhealthy snacks was somewhat lower in high-SES children, but the difference with middle- and low-SES children was insignificant. Nevertheless, we did see a significant positive association between school's performance and nutritional quality of snacking. Since education is a key aspect of children's present and future well-being, we can assume this variable denotes parental support in other dimensions of well-being, including nutrition and health status. Parents committed to their children's education may be parents committed to their children's lifestyles.

\section{Implications for policy}

Our results may have significant implications for government policy. They not only support the idea of a positive association between dietary patterns consistent with the 
food guidelines and academic outcomes, but also suggest that encouraging the consumption of snacks within the guidelines may be a simple method of advancing students' performance in Mathematics and Language. According to the Chilean Ministry of Education, an important proportion of students shows important deficiencies in both fields ${ }^{(32)}$.

A further implication is that the link between diet and students' academic performance might play a major role to promote sustained behavioural changes regarding lifestyles. Aiming to improve the population's health and to prevent chronic diseases, several countries have developed food and nutrition guidelines. The underlying assumption is that if people are aware of the risks and that healthier choices exist, they will make wise decisions and modify their behaviour. However, in spite of the availability of information and healthy alternatives, people usually fail in making choices that truly advance their health and well-being. Behavioural scientists and behavioural economists have identified psychological biases that explain the anomalous health decision making ${ }^{(53,54)}$. Reluctance to paternalism (forced choices), the tendency to choose the default option and the tendency to overvalue current benefits and costs relative to future ones are among the biases that prevent people from making smart health decisions no matter what information and knowledge they have about these matters. Given that reality, some positive external properties of healthy choices may be highlighted to increase the present value of healthy lifestyles. In previous works, we found a positive association of regular exercise with academic outcomes ${ }^{(55,56)}$. Whereas the health implications of unhealthy lifestyles can take time to materialize, the academic benefits may be easily anticipated and, therefore, provide stronger incentives to make healthy choices.

Likewise, these results are interesting since they focus on school snacks which may be easier to address for future interventions than the whole diet. Two years after enactment of the Healthy Foods Act, the Chilean Ministry of Health is still working on the implementation regulations. One of the most difficult issues has been controlling the food sold and advertised in school settings. Due to the association of snacking at school with children's academic outcomes, the present findings may reduce parental reluctance to the regulation of school kiosks, which has been traditionally perceived as contrary to freedom of choice. Indeed, when it comes to regulating the foods offered in schools, parents usually state that shaping children's dietary habits is not a responsibility for the government ${ }^{(5)}$.

Finally, these findings may pave the path for a major involvement of educational agencies in health advancement. In 1995, the WHO set up the Global School Health Initiative. A call was made to provide healthy settings for learning and to encourage governmental organizations, education officials, teachers and parents to get involved in the goal of increasing the number of schools that serve as a point of entry for health promotion and nutrition interventions ${ }^{(57,58)}$.
Later, the 2004 Global Strategy on Diet, Physical Activity and Health reckoned that health behaviours can be influenced especially in schools and educational institutions, encouraging governments to adopt policies to support healthy diets at school and limit the availability of unhealthy foods ${ }^{(59)}$. Although school health and nutrition strategies have been implemented in Chile since the late 1990s, including the Vida Chile Program, the Global Strategy for Obesity (EGO-Chile) Schools Program and the Elige Vivir Sano Program, they have not been successful, judging by the obesity rates in children and adolescents. On the one hand, there is a lack of coordination among agencies, from local and regional to central government ${ }^{(60)}$. On the other, the foremost aim of these strategies has been the population's health, which is not considered to be a major goal by schools and educational agencies.

\section{Strengths and limitations}

The present research provides results supporting the notion of a positive link between unhealthy eating and academic achievement, although more investigation is needed to establish the directionality of this relationship. A further strength is that we provide evidence that may be useful for middle-income and developing countries undergoing nutritional and epidemiological transitions; while most studies have been conducted in the developed world, evidence for the developing world is still lacking. Last, we measured students' academic performance using a nationwide standardized test.

In spite of these strengths, several limitations should be acknowledged. Our sample is not nationally representative; however, the Santiago Metropolitan Region accounts for $55 \%$ of the Chilean school-age population, and our sample is representative of the target population by type of school (private, partially subsidized and public) and school's academic performance in the SIMCE 2009. Second, although we accounted for sex, grade, nutritional status, SES and the school's performance as possible confounders, due to data constraints we did not consider the mediating effect of other important influences such as breast-feeding duration, parental education and environment. A further weakness has to do with the fact that 5 th graders answered the FFQ with their parents. This may introduce certain bias since parents are unable to truly monitor their children's food choices at school. Yet, scientific evidence shows that children's preferences and eating habits are highly influenced by familial environment and parental behaviours regarding lifestyles ${ }^{(51,52)}$. Finally, subsequent follow-up and longitudinal studies should address this issue and provide evidence on the temporality of this relationship.

\section{Acknowledgements}

Acknowledgements: The authors wish to acknowledge the ongoing commitment of the participants, their families and 
schools. They also thank to the Ministry of Education (Chile) for providing part of the data used in this research and all of the people who contributed to the development of this project. Financial support: This research received financial support from the National Commission for Scientific and Technological Research (CONICYT), Chile (grant FONDECYT $n^{\mathbf{0}}$ 1100431). CONICYT had no role in the design, analysis or writing of this article. Conflict of interest: None. Authorship: P.C.-B. conceived the study, collected the literature, analysed the data and wrote the manuscript; R.B. and D.I. were involved in the study design, assisted in data interpretation and provided input for the manuscript; Y.O. was in charge of the sampling process and assisted in statistical analysis of the data. All authors had final approval of the submitted version. Ethics of human subject participation: This study was approved by the Committee on Ethics in Studies in Humans of the Institute of Nutrition and Food Technology (INTA), University of Chile, and ratified by the Committee on Bioethics of the National Fund for Scientific and Technologic Development (FONDECYT), Chile. Participants and their parents gave informed and written consent.

\section{References}

1. Walker S, Wachs T, Gardner J et al. (2007) Child development: risk factors for adverse outcomes in developing countries. Lancet 369, 145-157.

2. Bougma K, Aboud F, Harding K et al. (2013) Iodine and mental development of children 5 years old and under: a systematic review and meta-analysis. Nutrients $\mathbf{5}$, 1384-1416.

3. Gupta N, Goel K, Shah P et al. (2012) Childhood obesity in developing countries: epidemiology, determinants, and prevention. Endocr Rev 33, 48-70.

4. Bonilla-Chacin M, Marcano-Vázquez L, Sierra R et al. (2013) Dietary Patterns and Non-Communicable Diseases in Selected Latin American Countries. Health, Nutrition, and Population Discussion Paper no. 80559. Washington, DC: World Bank.

5. Fraser B (2013) Latin America countries crack down on junk food. Lancet 382, 384-385.

6. Morris M, Evans D, Bienias J et al. (2004) Dietary fat intake and 6-year cognitive change in an older biracial community population. Neurology 62, 1573-1579.

7. Eskelinen M, Ngandu T, Helkala E et al. (2008) Fat intake at midlife and cognitive impairment later in life: a populationbased CAIDE study. Int J Geriatr Psychiatr 23, 741-747.

8. Nabb S \& Benton D (2006) The influence on cognition of the interaction between the macro-nutrient content of breakfast and glucose tolerance. Physiol Behav 87, 16-23.

9. Benton D, Maconie A \& Williams C (2007) The influence of the glycaemic load of breakfast on the behaviour of children in school. Physiol Behav 92, 717-724.

10. Smith M \& Foster J (2008) The impact of a high versus a low glycaemic index breakfast cereal meal on verbal episodic memory in healthy adolescents. Nutr Neurosci 11, 219-227.

11. Gale C, Martyn C, Marriott L et al. (2009) Dietary patterns in infancy and cognitive and neuropsychological function in childhood. J Child Psychol Psychiatry 50, 816-823.

12. Jurdak N \& Kanarek R (2009) Sucrose-induced obesity impairs novel object recognition learning in young rats. Physiol Behav 96, 1-5.
13. Kanoski S \& Davidson T (2011) Western diet consumption and cognitive impairment: links to hippocampal dysfunction and obesity. Physiol Behav 103, 59-68.

14. Northstone K, Joinson C, Emmett P et al. (2012) Are dietary patterns in childhood associated with IQ at 8 years of age? A population-based cohort study. J Epidemiol Community Health 66, 624-628.

15. Smithers L, Golley R, Mittinty M et al. (2012) Dietary patterns at 6,15 and 24 months of age are associated with IQ at 8 years of age. Eur J Epidemiol 27, 525-535.

16. Smithers L, Golley R, Mittinty M et al. (2013) Do dietary trajectories between infancy and toddlerhood influence IQ in childhood and adolescence? Results from a prospective birth cohort study. PLoS One 8, e58904.

17. Theodore R, Thompson J, Waldie K et al. (2009) Dietary patterns and intelligence in early and middle childhood. Intelligence 37, 506-513.

18. Nyaradi A, Li J, Hickling S et al. (2013) Diet in the early years of life influences cognitive outcomes at 10 years: a prospective cohort study. Acta Paediatr 102, 1165-1173.

19. Taras H (2005) Nutrition and student performance at school. J Sch Health 75, 199-213.

20. Dewey K \& Begum K (2011) Long-term consequences of stunting in early life. Matern Child Nutr 7, 5-18.

21. Sigfúsdóttir I, Krisjánsson A \& Allegrante J (2007) Health behaviours and academic achievement in Icelandic school children. Health Educ Res 22, 70-80.

22. Kristjánsson A, Sigfúsdóttir I \& Allegrante J (2010) Health behavior and academic achievement among adolescents: the relative contribution of dietary habits, physical activity, body mass index, and self-esteem. Health Educ Behav 37, 51-64.

23. Øverby N, Lüdemann E \& Høigaard R (2013) Self-reported learning difficulties and dietary intake in Norwegian adolescents. Scand J Public Health 41, 754-760.

24. Øverby N \& Høigaard R (2012) Diet and behavioral problems at school in Norwegian adolescents. Food Nutr Res 2012, 56 .

25. Florence M, Asbridge M \& Veugelers P (2008) Diet quality and academic performance. J Sch Health $\mathbf{7 8}$, 209-215.

26. Albala C, Vio F, Kain J et al. (2002) Nutrition transition in Chile: determinants and consequences. Public Health Nutr 5, 123-128.

27. Muzzo S, Cordero J, Ramírez I et al. (2004) Trends in nutritional status and stature among school age children in Chile. Nutrition 20, 867-873.

28. Vio F, Albala C \& Kain J (2008) Nutrition transition in Chile revisited. Mid-term evaluation of obesity goals for period 2000-2010. Public Health Nutr 11, 405-412.

29. Burrows R, Díaz E, Sciaraffia V et al. (2008) Dietary intake and physical activity in school age children. Rev Med Chile 136, 53-63.

30. Correa-Burrows P, Burrows R, Uauy R et al. (2012) Health production and risk of obesity among Chilean adolescents: understanding health related behaviors in youth. Health $\mathbf{4}$, 1413-1419.

31. Ministerio de Salud (2010) Tablas Chilenas de Composición Química de los Alimentos. Santiago de Chile: MINSAL.

32. Ministerio de Educación (2010) Resultados Nacionales del SIMCE 2009. Unidad de Currículum y Evaluación. Santiago de Chile: MINEDUC.

33. Gibson R (1990) Principles of Nutritional Assessment. Oxford: Oxford University Press.

34. Kuczmarski RJ, Ogden CL, Guo SS et al. (2002) 2000 CDC growth charts for the United States: methods and development. Vital Health Stat 11 issue 246, 1-190.

35. Álvarez M, Muzzo S \& Ivanovic D (1985) Escala para medición del nivel socioeconómico en el área de la salud. Rev Med Chil 113, 243-249. 
36. Bustos N, Kain J, Leyton B et al. (2010) Snacks usually consumed by children from public schools: motivations for their selection. Rev Chil Nutr 37, 178-183.

37. Olivares S, Yañez C \& Díaz N (2003) Food advertising and food behavior in school-age children from 5 th to 8 th grade. Rev Chil Nutr 30, 36-42.

38. Bustos N, Kain J, Leyton B et al. (2011) Changes in food consumption pattern among Chilean school children after the implementation of a healthy kiosk. Arch Latinoam Nutr 61, 302-307.

39. Salinas J, Correa F \& Vio F (2013) Regulatory framework for promoting healthy food intake in basic schools in Chile. Rev Chil Nutr 40, 274-282.

40. Nyaradi A, Foster J, Hickling S et al. (2014) Prospective association between dietary patters and cognitive performance during adolescence. J Child Psychol Psychiatry 55, 1017-1024.

41. Howard A, Robinson M, Smith G et al. (2011) ADHD is associated with a Western dietary pattern in adolescents. J Atten Disord 15, 403-411.

42. Davidson T, Chan K, Jarrard L et al. (2009) Contributions of the hippocampus and medial prefrontal cortex to energy and body weight regulation. Hippocampus 19, 235-252.

43. Kanoski S, Zhang Y, Zheng W et al. (2010) The effects of a high-energy diet on hippocampal function and blood-brain barrier integrity in the rat. J Alzheimers Dis 21, 207-219.

44. Feinstein L, Sabates R, Sorhaindo A et al. (2008) Dietary patterns related to attainment in school: the importance of early eating patterns. J Epidemiol Community Health 62, 734-739.

45. Datar A \& Sturm R (2004) Childhood overweight and parent- and teacher-reported behavior problems: evidence from a prospective study of kindergartners. Arch Pediatr Adolesc Med 158, 804-810.

46. Datar A \& Sturm R (2006) Childhood overweight and elementary school outcomes. Int J Obes (Lond) 30, 1449-1460.

47. Taras H \& Potts-Datema W (2005) Obesity and student performance at school. J Sch Health 75, 291-295.

48. Darmon N \& Drewnowski A (2008) Does social predict quality of diet? Am J Clin Nutr 87, 1107-1117.

49. Nilsen S, Krokstad S, Holmen T et al. (2010) Adolescents' health-related dietary patterns by parental socio-economic position, The Nord-Trøndelag Health Study (HUNT). Eur J Public Health 20, 299-305.

50. Fernández-Alvira J, Bammann K, Pala V et al. (2014) Country-specific dietary patterns and associations with socioeconomic status in European children: the IDEFICS Study. Eur J Clin Nutr 68, 811-821.

51. Savage J, Fisher J \& Birch L (2007) Parental influence on eating behavior: conception to adolescence. J Law Med Ethics 35, 22-34.

52. Ambrosini G, Oddy W, Robinson M et al. (2009) Adolescents' dietary patterns are associated with lifestyles and family psycho-social factors. Public Health Nutr 12, $1807-1815$.

53. Just D \& Payne C (2009) Obesity: can behavioral economics help? Ann Behav Med 38, 47-55.

54. Gittelsohn J \& Lee K (2013) Integrating educational, environmental, and behavioral economics strategies may improve the effectiveness of obesity interventions. Appl Econ Perspect Policy 35, 52-68.

55. Correa-Burrows P, Burrows R, Orellana Y et al. (2014) Achievement in mathematics and language is linked to regular physical activity: a population study in Chilean youth. J Sports Sci 32, 1631-1638.

56. Burrows R, Correa P, Ibaceta C et al. (2014) Scheduled physical activity is associated with better academic performance in Chilean school-age children. J Phys Act Health (Epublication ahead of print version).

57. Jones J \& Furner M (1998) Health-Promoting School. A Healthy Setting for Living, Learning and Working. WHO/ HPR/HEP/98.4. Geneva: Division of Health Promotion, Education and Communication, Health Education and Health Promotion Unit, WHO.

58. Aldinger C \& Jones J (1998) Healthy Nutrition: An Essential Element of a Health-Promoting School. WHO/HPR/HEP/ 98.3. Geneva: Division of Health Promotion, Education and Communication, Health Education and Health Promotion Unit, WHO.

59. World Health Organization (2004) Global Strategy on Diet, Physical Activity and Health. Geneva: WHO.

60. Salinas J \& Vio F (2011) Health and nutrition programs without a state policy: the case of school health promotion in Chile. Rev Chil Nutr 38, 100-116. 